\title{
Unmet Needs in Anticoagulant Therapy: Potential Role of Rivaroxaban
}

\author{
John W. Eikelboom ${ }^{\text {a, b }}$, Stuart J. Connolly ${ }^{\mathrm{a}}$
}

\begin{abstract}
The new generation of non-vitamin $\mathrm{K}$ antagonist oral anticoagulants (NOACs) have been welcomed as a convenient alternative to warfarin. Three new oral anticoagulants, dabigatran etexilate, rivaroxaban and apixaban have been approved for the prevention of stroke and systemic embolism (SSE) in patients with atrial fibrillation (AF) and the prevention of venous thromboembolic events (VTEs) in patients who have undergone elective hip or knee replacement surgery. Dabigatran etexilate and rivaroxaban are also indicated for the treatment of VTE and the long-term prevention of recurrent deep vein thrombosis (DVT) and pulmonary embolism (PE). A fourth agent, edoxaban, has been successfully tested for several indications but is not yet approved for use in North America or Europe. Building on these successes, new trials are planned to address remaining unmet needs and knowledge gaps. This paper examines the unresolved issues in anticoagulant therapy with a focus on planned and ongoing trials.
\end{abstract}

Keywords: Anticoagulation; Dabigatran; Rivaroxaban; Apixaban; Unmet needs

\section{Introduction}

For more than 60 years, vitamin K antagonists (VKAs), such as warfarin, have been the only oral anticoagulants available for clinical use. Warfarin is effective for the prevention and treatment of thrombosis but has drawbacks that limit its uptake and use [1]. Three recently introduced non-vitamin K antagonist oral anticoagulants (NOACs), dabigatran etexilate, rivaroxaban and apixaban, now offer clinicians and patients muchneeded alternatives to warfarin. A fourth NOAC, edoxaban, has successfully completed testing for several indications but

Manuscript accepted for publication June 25, 2015

aPopulation Health Research Institute, McMaster University and Hamilton Health Sciences, 237 Barton St. E., Hamilton, ON L8L 2X2, Canada

${ }^{b}$ Corresponding Author: John W. Eikelboom, Population Health Research Institute, McMaster University and Hamilton Health Sciences, 237 Barton St. E., Hamilton, ON L8L 2X2, Canada. Email: eikelbj@mcmaster.ca

doi: http://dx.doi.org/10.14740/cr413w is not yet approved and is not further discussed in this paper.

NOACs have been successfully tested as alternatives to standard therapies in randomized trials involving more than 135,000 patients and are approved around the world for prevention of stroke and systemic embolism (SSE) in patients with atrial fibrillation (AF), prevention of venous thromboembolism (VTE) in patients who have undergone elective hip or knee replacement surgery; the initial and long-term treatment of VTE; and the prevention of atherothrombotic events after an acute coronary syndrome (ACS).

Despite the established efficacy of NOACs for multiple indications, knowledge gaps remain (Fig. 1). To help bridge these gaps, new studies are planned or ongoing. This paper explores unmet needs in anticoagulant therapy and summarizes the ongoing rivaroxaban clinical trial program for both established (Table 1) and new indications (Table 2).

\section{Unresolved Issues in Established Indications}

\section{Stroke prevention in patients with $\mathrm{AF}$}

Dabigatran, rivaroxaban and apixaban have been shown in the RE-LY, ROCKET-AF and ARISTOTLE trials, respectively, to be non-inferior or superior to warfarin, with similar or reduced rates of major bleeding [2-4]. All NOACs reduced intracranial bleeding, the most feared complication of warfarin therapy, and demonstrated favorable effects on mortality. Two related areas that require further study include $\mathrm{AF}$ patients undergoing procedures (restore sinus rhythm, device implantation or ablation), and those with thrombosis in the left atrium (LA) or left atrial appendage (LAA).

\section{Cardioversion}

Clinicians have extensive experience using warfarin in patients undergoing cardioversion. Data supporting the use of NOACs for patients undergoing cardioversion are limited to secondary analyses from the major registration trials and observational studies [5-7]. Post-hoc analyses of RE-LY $(n=1,270)$, ROCKET-AF $(n=143)$ and ARISTOTLE $(n=540)$ suggest NOACs are safe and effective for patients undergoing cardioversion, with similar rates of stroke and bleeding compared to warfarin 


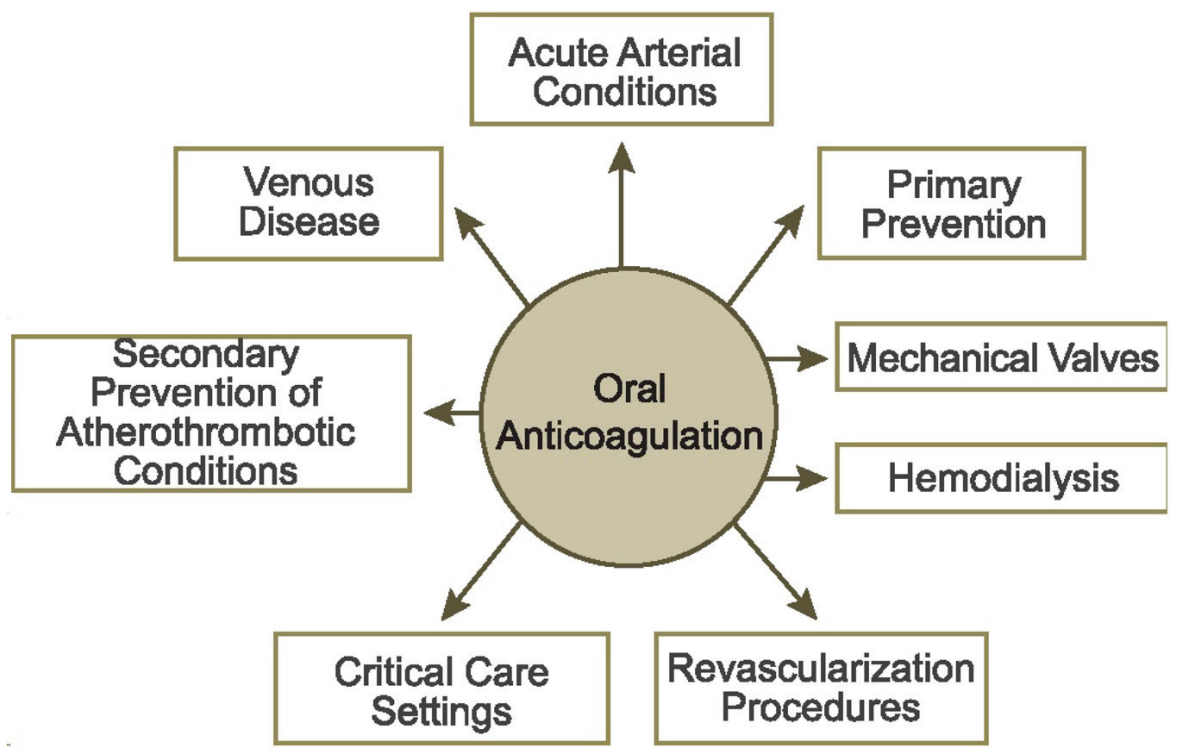

Figure 1. Clinical settings for oral anticoagulation. Clinical questions about the management of the NOACs exist in each of these settings.

[5-7]. However, the number of patients in these analyses was modest, particularly for rivaroxaban and apixaban.

Recently, the X-VeRT trial found rivaroxaban to be an effective and safe alternative to VKAs for the prevention of major cardiovascular $(\mathrm{CV})$ events in patients with AF undergoing elective cardioversion (early or delayed strategy) [8]. In this trial, 1,500 patients scheduled for cardioversion were randomized to rivaroxaban $20 \mathrm{mg}$ QD (15 mg in those with creatinine clearance $30-49 \mathrm{~mL} / \mathrm{min}$ ) or warfarin (INR $2-3$ ). The primary efficacy outcome of composite of stroke, transient ischemic attack (TIA), non-central nervous system (non-CNS) systemic embolism (SE), myocardial infarction (MI) and CV death occurred in $0.51 \%$ and $1.02 \%$ of patients in the rivaroxaban and VKA arms, respectively. The primary safety outcome of major bleeding occurred in $0.6 \%$ and $0.8 \%$ of patients, respectively. The results of this trial suggest that rivaroxaban may allow for prompter cardioversion.

A similar study is planned with apixaban (NCT02100228), and another study is testing the utility of routine transesophageal echocardiogram (TEE) in patients treated with dabigatran undergoing cardioversion (NCT01593150).

\section{Catheter ablation}

For patients undergoing catheter ablation, anticoagulation with warfarin has been the standard of care. Anticoagulation therapy is generally interrupted 5 days prior to the procedure and recommenced post-procedure with administration of bridging low molecular weight heparin (LMWH) during the period of interruption. A meta-analysis comparing dabigatran to warfarin in patients undergoing catheter ablation found a similar incidence of thromboembolic events and major bleeding compared to warfarin, with low event rates overall [9]. Similar experience has been reported with rivaroxaban [5]; however, no data are available for apixaban in this setting. Additional data are needed to strengthen the rationale to use NOACs in patients undergoing ablation and to determine the optimal peri-procedural management strategy (continued vs. interrupted use of NOAC, timing of stopping and restarting, need for TEE prior to the procedure, etc.).

VENTURE-AF (NCT01729871) is an open label, multicenter trial comparing uninterrupted rivaroxaban with usual care in patients with persistent or paroxysmal non-valvular AF scheduled to undergo their first catheter ablation [10]. Two hundred and fifty patients are being randomized to receive uninterrupted rivaroxaban $20 \mathrm{mg}$ QD or warfarin for at least 28 days prior to catheter ablation, followed by $30 \pm 5$ days of treatment postprocedure. All patients will receive intravenous heparin during catheter ablation. Prior to catheter ablation, patients are required to demonstrate sufficient anticoagulation during the 3 weeks before randomization or undergo a TEE. This trial is not powered for efficacy outcomes and the primary outcome is the incidence of major bleeding events $30 \pm 5$ days following the ablation procedure. This study has been completed and is awaiting results.

Studies investigating the safety and efficacy of uninterrupted dabigatran (RE-CIRCUIT; NCT02348723) or apixaban (AXAFA; NCT02227550) in patients with AF undergoing catheter ablation are also planned. The results of these trials are expected in 2016 and 2017, respectively.

\section{Device implantation}

Current guidelines recommend warfarin interruption and bridging therapy with heparin around the time of device implantation [11]. This approach has been superseded by the results of the recently published BRUISECONTROL trial which demonstrated superior safety of continuous compared with interrupted warfarin therapy at the time of pacemaker or ICD surgery [12].

There are limited data for NOACs in patients undergo- 
Table 1. Ongoing Studies With Rivaroxaban Addressing Unresolved Issues in Established Indications

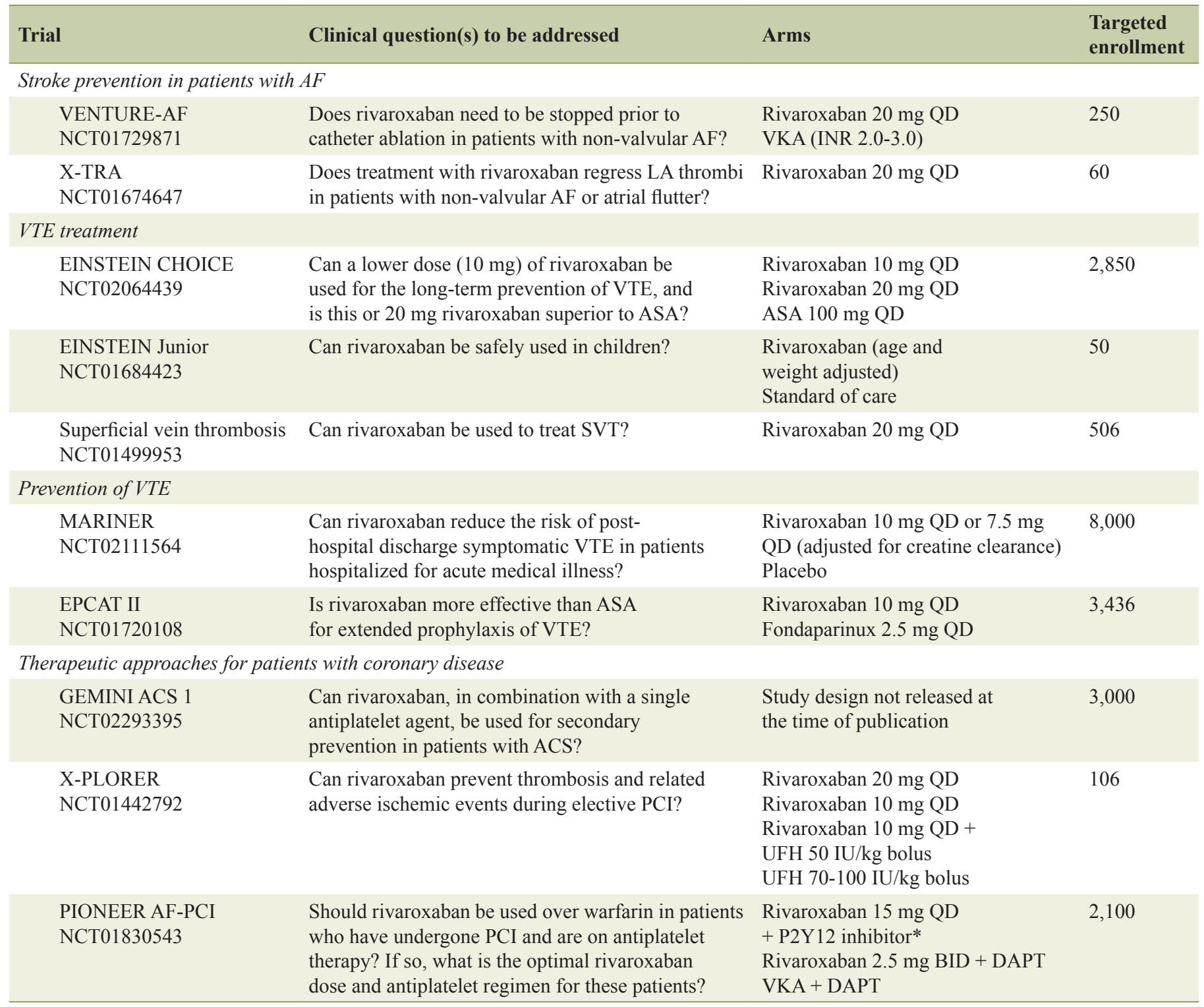

*P2Y12 inhibitor such as clopidogrel (75 mg QD). ACS: acute coronary syndrome; AF: atrial fibrillation; ASA: acetylsalicylic acid; DAPT: dual antiplatelet therapy; LA: left atrial; PCl: percutaneous coronary intervention; SVT: superficial vein thrombosis; UFH: unfractionated heparin; VKA: vitamin $\mathrm{K}$ antagonist; VTE: venous thromboembolic events.

ing device implantation and it is unclear if an NOAC must be stopped prior to the procedure and whether bridging with heparin is required [13]. Observational data suggest uninterrupted dabigatran during device implantation is safe, with no serious bleeding or thromboembolic events reported [14]. This approach is being further investigated in the ongoing BRUISECONTROL2 (NCT01675076) randomized controlled trial (RCT).

\section{LA/LAA thrombosis}

The identification of an LA or LAA thrombus poses a chal- lenging management problem in patients with AF. Conventional treatment involves the use of heparin or LMWH for at least 5 days overlapped by a VKA. Trials of NOACs for initial treatment of VTE used higher doses of rivaroxaban $(20 \mathrm{mg}$ QD) and apixaban (10 mg BID) for the first 1 - 3 weeks in order to ensure adequate suppression of coagulation $[15,16]$. It is unclear whether higher doses are also required in the initial management of cardiac thrombus. X-TRA (NCT01839357) is an observational study evaluating the use of rivaroxaban 20 $\mathrm{mg} \mathrm{QD}$ in 60 patients with LA/LAA thrombus. The primary outcome is resolution of LA/LAA thrombus after 6 weeks of treatment, as assessed by TEE. This study has been completed and is awaiting results. 
Table 2. Ongoing Studies With Rivaroxaban in Potential New Indications

\begin{tabular}{|c|c|c|c|}
\hline Trial & Clinical question(s) to be addressed & Arms & $\begin{array}{l}\text { Estimated } \\
\text { enrollment }\end{array}$ \\
\hline \multicolumn{4}{|c|}{ Secondary prevention of cardiovascular disease } \\
\hline $\begin{array}{l}\text { COMPASS } \\
\text { NCT01776424 }\end{array}$ & $\begin{array}{l}\text { Does rivaroxaban provide additional } \\
\text { cardioprotective benefits to high-risk patients? } \\
\text { Should rivaroxaban be used alone } \\
\text { or in combination with ASA in } \\
\text { patients with CAD or PAD? }\end{array}$ & $\begin{array}{l}\text { Rivaroxaban } 2.5 \mathrm{mg} \text { BID + ASA } \\
\text { Rivaroxaban } 5.0 \mathrm{mg} \text { BID } \\
\text { ASA } 100 \mathrm{mg} \text { QD }\end{array}$ & 19,500 \\
\hline \multicolumn{4}{|l|}{ Heart failure } \\
\hline $\begin{array}{l}\text { COMMANDER-HF } \\
\text { NCT01877915 }\end{array}$ & $\begin{array}{l}\text { Does adding low-dose rivaroxaban } \\
\text { to optimal medical therapy improve } \\
\text { outcomes in heart failure? }\end{array}$ & $\begin{array}{l}\text { Rivaroxaban } 2.5 \mathrm{mg} \text { BID }+ \text { single } \\
\text { or dual antiplatelet therapy } \\
\text { Single or dual antiplatelet therapy }\end{array}$ & 5,000 \\
\hline \multicolumn{4}{|l|}{ Confirmed or suspected HIT } \\
\hline $\begin{array}{l}\text { Heparin-induced thrombocytopenia } \\
\text { NCT01598168 }\end{array}$ & Can rivaroxaban be used to treat HIT? & $\begin{array}{l}\text { Rivaroxaban } 15 \mathrm{mg} \text { BID until } \\
\text { HIT excluded, followed by } \\
\text { rivaroxaban } 20 \mathrm{mg} \text { QD }\end{array}$ & 200 \\
\hline $\begin{array}{l}\text { NAVIGATE ESUS } \\
\text { NCT02313909 }\end{array}$ & $\begin{array}{l}\text { Is rivaroxaban more effective than } \\
\text { ASA atreducing the risk of recurrent } \\
\text { stroke and systemic embolism in } \\
\text { patients with a recent ESUS? }\end{array}$ & $\begin{array}{l}\text { Rivaroxaban } 15 \mathrm{mg} \text { QD } \\
\text { ASA } 100 \mathrm{mg} \text { QD }\end{array}$ & 7,000 \\
\hline \multicolumn{4}{|c|}{ Treatment of high-risk patients with non-disabling cerebrovascular events } \\
\hline $\begin{array}{l}\text { TRACE } \\
\text { NCT01923818 }\end{array}$ & $\begin{array}{l}\text { Should rivaroxaban be used over } \\
\text { ASA in patients following TIA } \\
\text { or minor ischemic stroke? }\end{array}$ & $\begin{array}{l}\text { ASA } 100 \mathrm{mg} \text { QD } \\
\text { Rivaroxaban } 5 \mathrm{mg} \\
\text { Rivaroxaban } 10 \mathrm{mg}\end{array}$ & 3,700 \\
\hline
\end{tabular}

ASA: acetylsalicylic acid; CAD: coronary artery disease; ESUS: embolic stroke of undetermined source; HIT: heparin-induced thrombocytopenia; PAD: peripheral artery disease; TIA: transient ischemic attack.

\section{VTE treatment}

Dabigatran, rivaroxaban and apixaban have demonstrated noninferiority to conventional therapy (subcutaneous enoxaparin followed by a VKA) for the initial and long-term treatment of VTE, with similar or superior safety profiles [15-18]. Ongoing clinical trials are exploring the optimal dose of rivaroxaban for extended VTE prevention and are investigating whether rivaroxaban can be used in patients with superficial vein thrombosis (SVT) and children with VTE.

\section{Extended duration treatment of VTE}

Extended treatment with dabigatran, rivaroxaban and apixaban is effective at reducing the risk of recurrent VTE $[16,17$, 19]; however, the optimal dose and duration of extended treatment is not clear. In AMPLIFY-EXT, patients who previously received 6 - 12 months of anticoagulant therapy were randomized to extended treatment with apixaban at the standard dose (5 mg BID) or lower dose (2.5 mg BID) [20]. The lower dose of apixaban was found to be as effective as the standard dose, with rates of bleeding similar to placebo. Standard doses of rivaroxaban and dabigatran were investigated in their respective extension trials. It remains unresolved whether a lower dose would preserve efficacy while reducing the risk of bleeding during extended treatment.

EINSTEIN-CHOICE (NCT02064439) is testing the efficacy of a reduced dose of rivaroxaban for extended duration VTE prevention. This trial will randomize 2,850 patients who have received 6 - 12 months anticoagulant therapy to rivaroxaban $10 \mathrm{mg}$ QD, rivaroxaban $20 \mathrm{mg}$ QD or acetylsalicylic acid (ASA) $100 \mathrm{mg}$ QD. In addition to informing on the safety and efficacy of a lower dose rivaroxaban strategy, this trial will also provide information on whether rivaroxaban is superior to ASA for long-term VTE prevention.

\section{Pediatric thrombosis}

Over the past 15 years, the frequency of VTE diagnosis in hospitalized children has increased 3- to 10-fold, from 0.3 - 28.8 cases per 10,000 admissions between 1992 and 2005 to 34 58 cases per 10,000 admissions between 2001 and 2007 [19, $21,22]$. Despite the increased burden of pediatric thrombosis, high quality evidence from RCTs concerning the optimal dose, efficacy and safety of commonly used anticoagulants, including unfractionated heparin (UFH), LMWH, warfarin and the NOACs is lacking. To help address this gap, EINSTEIN Junior (NCT01684423) is investigating the pharmacokinetic/ pharmacodynamic (PK/PD) properties, safety and efficacy of rivaroxaban in children with various manifestations of venous 
thrombosis. In this phase II study, children aged 6 - 17 are randomized to age- and body weight-adjusted rivaroxaban or standard of care for 30 days. The primary outcome is major and clinically relevant non-major bleeding. Study completion is expected in September 2015. Pediatric trials are also underway for dabigatran (NCT01895777) and apixaban (NCT01707394).

\section{Superficial vein thrombosis}

Superficial vein thrombosis affects approximately $3-11 \%$ of the general population (annual incidence is not known) and is associated with an increased risk of VTE [23, 24]. Anticoagulants reduce acute symptoms, prevent extension, and reduce the risk of progression to VTE [25]. Fondaparinux administered parenterally for 45 days is effective for the treatment of SVT, but must be injected, making it an inconvenient therapy for patients. The superficial vein thrombosis treated with rivaroxaban versus fondaparinux trial (NCT01499953) is randomizing 506 patients to rivaroxaban $10 \mathrm{mg}$ QD or fondaparinux $2.5 \mathrm{mg}$ QD for 45 days. The primary efficacy outcome is death from any cause and the primary safety outcome is major bleeding events. Study completion is expected in March 2017.

\section{Prevention of VTE}

Prophylactic anticoagulation to prevent VTE is standard of care following total hip replacement (THR) or total knee replacement (TKR) surgery. Dabigatran, apixaban and rivaroxaban are approved for these indications based on comprehensive clinical trial programs that collectively randomized more than 34,000 patients [26-38].

Emerging evidence indicates that ASA is also effective for VTE prophylaxis in patients undergoing major orthopedic surgery [39, 40]. The American College of Chest Physicians (ACCP) and American Academy of Orthopaedic Surgeons (AAOS) guidelines recommend ASA as an effective alternative to anticoagulants for VTE prevention, but its efficacy and safety relative to the NOACs is unknown [41-43]. The EPCAT II trial (NCT01720108) is randomizing 3,436 patients undergoing TKR or THR to either rivaroxaban $10 \mathrm{mg}$ QD or ASA $81 \mathrm{mg}$ QD for 9 days (TKR) or 30 days (THR). All patients will receive initial treatment with rivaroxaban for 5 days after surgery, prior to randomization. The primary efficacy outcome is symptomatic VTE and the primary safety outcome is major or clinically relevant non-major bleeding. The trial is expected to finish in December 2017.

\section{Prevention of VTE in the medically ill}

Patients who have been hospitalized for the treatment of acute medical illnesses are at high risk for the development of VTE after hospital discharge [44]. Extended duration rivaroxaban has been found to reduce the risk of VTE in patients hospitalized for an acute medical illness [45]. To determine if rivaroxa- ban can prevent symptomatic VTE in post-hospital discharge patients, the MARINER study (NCT02111564) will randomize 8,000 high-risk, medically ill patients to rivaroxaban 10 $\mathrm{mg}$ QD (7.5 mg QD if creatinine clearance is $30-49 \mathrm{~mL} / \mathrm{min}$ ) or placebo. The primary outcomes are time from randomization to the first occurrence of symptomatic VTE, VTE-related death or major bleeding. Study completion is expected in February 2017.

\section{Therapeutic approaches for patients with coronary dis- ease}

Following an ACS, patients are at an increased risk for recurrent $\mathrm{CV}$ events and require long-term dual antiplatelet therapy (DAPT; ASA plus P2Y12 inhibitor). Interest in the use of NOACs in this setting has increased as these patients also have persistently elevated markers of coagulation activation which is associated with an increased risk of recurrent major adverse CV events [46, 47].

The safety and efficacy of dabigatran and apixaban for the secondary prevention of ACS was investigated in the phase II RE-DEEM and phase III APPRAISE-2 trials, respectively [48, 49]. These trials found an increased risk of bleeding, with no benefit on the reduction in risk of recurrent ischemic events. Of note, APPRAISE-2 was halted early and no phase III trial with dabigatran was initiated in this setting.

In contrast, rivaroxaban (2.5 $\mathrm{mg}$ BID and $5 \mathrm{mg}$ BID in addition to ASA alone or ASA plus a thienopyridine) was found to significantly reduce the composite of death from $\mathrm{CV}$ causes, MI, or stroke [50]. Based on these findings, rivaroxaban $2.5 \mathrm{mg}$ BID was approved in Europe for the prevention of atherothrombotic events in patients after ACS. In followup to this study, the benefits of rivaroxaban in combination with single antiplatelet treatment for long-term secondary prevention after ACS will be investigated in the phase II GEMINI ACS 1 trial (NCT02293395). This trial will involve 3,000 patients, and if successful, the phase III trial, GEMINI ACS 2, will be undertaken to validate the results of the phase II study.

Patients with ACS routinely undergo percutaneous coronary intervention (PCI), with standard anticoagulant therapy consisting of UFH, enoxaparin or bivalirudin [51-53]. No studies have investigated the use of NOACs in patients undergoing PCI with stenting. As such, the question remains unanswered whether the NOACs can be used in these patients who also have an indication for DAPT.

\section{Elective PCI}

The X-PLORER trial (NCT01442792) is investigating whether rivaroxaban can be used without interruption during elective PCI in patients treated with DAPT. This trial is randomizing 106 patients to one of four arms: UFH (70 - $100 \mathrm{IH} / \mathrm{kg}$ bolus); rivaroxaban (10 $\mathrm{mg}$ single dose); rivaroxaban (20 $\mathrm{mg}$ single dose); or rivaroxaban (10 mg single dose) plus UFH (50 IU/kg bolus). Although severely underpowered, this trial will provide 


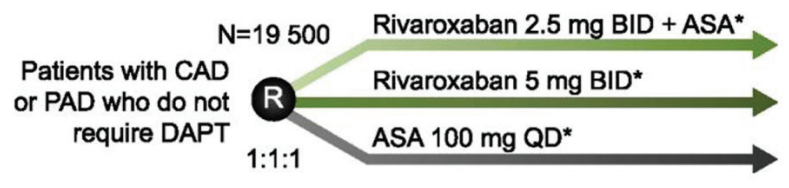

Figure 2. Study design of COMPASS. To assess the safety and efficacy of rivaroxaban for the prevention of MI, stroke, and CV death, patients with coronary artery disease (CAD) or peripheral artery disease (PAD), who do not require dual antiplatelet therapy (DAPT), are randomized to rivaroxaban $2.5 \mathrm{mg}$ BID + acetylsalicylic acid (ASA) $100 \mathrm{mg}$ QD; rivaroxaban $5 \mathrm{mg}$ BID; or ASA $100 \mathrm{mg}$ QD. *Patients in each arm are also randomized to pantoprazole $40 \mathrm{mg}$ QD or placebo to investigate if safety can be improved by the addition of a proton pump inhibitor.

some information on the efficacy of rivaroxaban compared with heparin for prevention of catheter thrombosis. Earlier trials have shown the selective factor Xa inhibitor, fondaparinux, to be associated with an increase in catheter thrombosis compared with enoxaparin $[27,28]$. The increased risk of catheter thrombosis with fondaparinux was prevented by the use of a small dose of heparin at the time of the procedure $[53,54]$. It is unclear whether rivaroxaban might also be associated with increased catheter thrombosis and whether the use of a small heparin bolus may obviate this risk.

\section{PCI in patients with an indication for anticoagulant therapy}

The optimal antithrombotic therapy post-PCI with stenting in patients who require chronic oral anticoagulation is uncertain [55]. DAPT is required to prevent stent thrombosis but the combination of a VKA and DAPT greatly increases the risk of bleeding [56, 57]. The WOEST trial demonstrated that the combination of warfarin and clopidogrel reduces the risk of bleeding without increasing thrombotic events as compared to triple therapy with warfarin + clopidogrel + ASA in patients undergoing coronary artery stenting [58].

NOACs are an attractive alternative to warfarin in patients with an indication for anticoagulation who undergo PCI with stenting because they produce less bleeding. Additionally, both rivaroxaban and apixaban (factor Xa inhibitors) reduce the risk of stent thrombosis in patients with ACS. However, the efficacy of NOACs in patients with an indication for both DAPT and therapeutic dose anticoagulation has yet to be formally tested $[49,50]$.

The RE-DUAL PCI trial (NCT02164864) is testing the efficacy and safety of dabigatran post-PCI. This trial will randomize 8,520 patients with AF who undergo PCI with stenting to dabigatran dual therapy (dabigatran + clopidogrel or ticagrelor) or warfarin triple therapy (warfarin + ASA + clopidogrel or ticagrelor). Additionally, PIONEER AF-PCI (NCT01830543) is testing the safety of rivaroxaban in patients with non-valvular AF who have undergone PCI. This trial is randomizing 2,100 patients to: 12 months of rivaroxaban 15 mg QD + P2Y12 inhibitor; 1, 6 or 12 months of rivaroxaban $2.5 \mathrm{mg}$ BID + DAPT, followed by rivaroxaban $15 \mathrm{mg}+$ ASA for a total of 12 months; or 1, 6 or 12 months of VKA + DAPT, followed by VKA + ASA for a total of 12 months. Final data collection for this study is expected in August 2016. A similar trial is also planned with apixaban.

\section{New Indications in Areas of Unmet Need}

\section{Secondary prevention of cardiovascular disease}

Coronary artery disease (CAD) is the most common cause of CV disease, responsible for 7.3 million deaths annually [59, 60]. Patients with established CV disease are at increased risk of MI, stroke, and CV death [61]. ASA is effective for CV prevention, but despite its routine use, patients continue to have platelet and coagulation activation and high rates of $\mathrm{CV}$ events [62-64]. Previous trials aimed at improving therapy by replacing ASA with clopidogrel, combining ASA with a second antiplatelet agent or combining ASA with warfarin have produced disappointing results [65-67]. Rivaroxaban is effective for prevention of MI, stroke or CV death in patients with ACS and rivaroxaban-based therapy has the potential to improve efficacy for $\mathrm{CV}$ prevention compared with ASA alone.

The COMPASS trial (NCT01776424) is randomizing 21,400 patients with CAD or peripheral artery disease (PAD) to receive rivaroxaban $2.5 \mathrm{mg}$ BID + ASA $100 \mathrm{mg} \mathrm{QD}$, rivaroxaban $5 \mathrm{mg}$ BID or ASA $100 \mathrm{mg}$ QD for prevention of MI, stroke or CV death (Fig. 2). A second factorial randomization is testing whether pantoprazole $40 \mathrm{mg}$ QD compared with placebo can prevent a composite of gastrointestinal complications and thereby improve the safety of antithrombotic therapy in this population. COMPASS is also testing whether rivaroxaban-based therapy is superior to aspirin for prevention of graft failure following coronary artery bypass grafting $(\mathrm{CABG})$ surgery. A substudy, COMPASS MIND, is examining whether rivaroxaban can prevent covert brain ischemia and related cognitive decline. Study completion is expected in February 2018.

\section{Heart failure}

Heart failure (HF) is one of the leading causes of hospitalization and is associated with an annual mortality rate of up to $50 \%$ in Canada $[68,69]$. Patients with HF are at increased risk of thromboembolic complications such as stroke, myocardial ischemia and death [70-72]. Trials with warfarin have produced modest reductions in CV events at the cost of substantial increases in bleeding [72-76]. No large scale clinical trials have investigated the NOACs in this setting. The COMMANDERHF trial (NCT01877915) is randomizing 5,000 patients with a history of CAD, recently hospitalized for an HF exacerbation, 


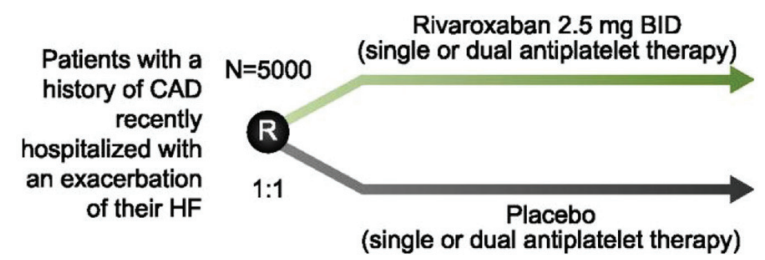

Figure 3. Study design of COMMANDER-HF. To determine whether rivaroxaban reduces the risk of MI, stroke or death, patients with a history of coronary artery disease (CAD) or those recently hospitalized for an exacerbation of their heart failure (HF) are randomized to rivaroxaban $2.5 \mathrm{mg}$ BID or placebo in addition to their current standard of care.

to either rivaroxaban $2.5 \mathrm{mg}$ BID or placebo on a background of optimal medical therapy, including single or dual antiplatelet therapy (Fig. 3). The primary outcome is the composite of MI, stroke, or all-cause mortality. This study is expected to be completed in April 2017.

\section{Confirmed or suspected HIT}

Type II heparin-induced thrombocytopenia (HIT) is triggered by an immune response to heparin and can lead to limb- or lifethreatening thromboembolic complications. Although HIT is uncommon, suspected HIT warrants discontinuation of heparin and treatment with an alternative anticoagulant [77]. Nonheparin anticoagulants: lepirudin, argatroban and danaparoid, are recommended for the treatment of HIT or suspected HIT but are expensive and require parenteral administration. An oral alternative would provide an attractive option that would be more convenient and less expensive.

The rivaroxaban for treatment of patients with suspected or confirmed HIT trial (NCT01598168) is examining the incidence of new symptomatic venous and arterial thromboembolism in 200 patients with intermediate or high clinical probability of HIT (4T's score $\geq 4$ ). These patients are being treated with rivaroxaban $15 \mathrm{mg}$ BID until HIT is excluded or the platelet count has recovered. After recovery of the platelet count, patients with confirmed HIT receive rivaroxaban $20 \mathrm{mg}$ QD until day 30 .

Stroke prevention in patients with embolic stroke of undetermined source (ESUS)

Strokes resulting from unknown sources comprise approximately $25 \%$ of all ischemic strokes, yet there remains limited evidence for secondary prevention strategies [78]. Randomized trials investigating oral anticoagulants for secondary prevention in patients with ESUS are warranted. NAVIGATE ESUS (NCT02313909) will evaluate whether rivaroxaban 15 $\mathrm{mg}$ QD is superior to aspirin $100 \mathrm{mg}$ QD in reducing the risk of recurrent stroke and systemic embolic events in 7,000 patients with a recent ESUS. The results of this trial are expected in 2018. A similar trial is also planned with dabigatran (RESPECT ESUS; NCT02239120); this study is currently recruiting patients with final data collection planned for November 2017.

\section{Treatment of high-risk patients with non-disabling CV events}

Patients who experience a TIA or non-disabling ischemic stroke are at an increased risk of early, recurrent stroke [79]. Early administration of ASA is recommended to improve outcomes in these patients but is only modestly effective [79-83]. Emerging evidence suggests that early intensive therapy with DAPT is more effective than ASA alone and does not increase the risk of bleeding [84]. Guidelines recommend against the use of heparin and warfarin because of concerns about an increased risk of intracranial bleeding $[82,85]$. The NOACs are an attractive option in patients with stroke because they are at least as effective as warfarin for prevention of thromboembolic events and are associated with a substantially lower risk of intracranial bleeding.

Rivaroxaban is being investigated for the treatment for nondisabling CV events in the Chinese TRACE study (NCT01923818). This trial is randomizing 3,700 patients to 30 days of ASA $100 \mathrm{mg}$, rivaroxaban $5 \mathrm{mg}$, or rivaroxaban $10 \mathrm{mg}$. The primary outcome is recurrent stroke at 90 days.

\section{Summary and Conclusion}

Recent years have seen rapid advancement in new anticoagulant therapies for patients at risk of thromboembolic events. The NOACs have shown to be at least as effective as standard therapies across a broad range of indications, but many unanswered questions and unmet needs remain. New trials are dedicated to addressing these unmet needs in populations spanning established and potential new indications.

Rivaroxaban is currently being tested in clinical trials involving more than 54,000 patients and studies with dabigatran and apixaban are also ongoing. As data from these trials become available, we will begin to bridge the existing knowledge gaps and gather insight on optimal patient care in diverse clinical settings.

\section{Acknowledgement}

The authors thank MEDUCOM Health Inc. for providing editorial and logistical support. The authors had complete editorial independence and take full responsibility for the content of this publication. 


\section{Funding}

Publication of this article was supported by Bayer Inc., who provided financial support to MEDUCOM Health for costs associated with logistics of manuscript preparation and submission.

\section{Conflict of Interest}

None.

\section{References}

1. Ageno W, Gallus AS, Wittkowsky A, Crowther M, Hylek EM, Palareti G. Oral anticoagulant therapy: Antithrombotic Therapy and Prevention of Thrombosis, 9th ed: American College of Chest Physicians EvidenceBased Clinical Practice Guidelines. Chest. 2012;141(2 Suppl):e44S-88S.

2. Granger CB, Alexander JH, McMurray JJ, Lopes RD, Hylek EM, Hanna M, Al-Khalidi HR, et al. Apixaban versus warfarin in patients with atrial fibrillation. $\mathrm{N}$ Engl J Med. 2011;365(11):981-992.

3. Connolly SJ, Ezekowitz MD, Yusuf S, Eikelboom J, Oldgren J, Parekh A, Pogue J, et al. Dabigatran versus warfarin in patients with atrial fibrillation. N Engl J Med. 2009;361(12):1139-1151.

4. Patel MR, Mahaffey KW, Garg J, Pan G, Singer DE, Hacke W, Breithardt G, et al. Rivaroxaban versus warfarin in nonvalvular atrial fibrillation. $\mathrm{N}$ Engl J Med. 2011;365(10):883-891.

5. Piccini JP, Stevens SR, Lokhnygina Y, Patel MR, Halperin JL, Singer DE, Hankey GJ, et al. Outcomes after cardioversion and atrial fibrillation ablation in patients treated with rivaroxaban and warfarin in the ROCKET AF trial. J Am Coll Cardiol. 2013;61(19):1998-2006.

6. Flaker G, Lopes RD, Al-Khatib SM, Hermosillo AG, Hohnloser SH, Tinga B, Zhu J, et al. Efficacy and safety of apixaban in patients after cardioversion for atrial fibrillation: insights from the ARISTOTLE Trial (Apixaban for Reduction in Stroke and Other Thromboembolic Events in Atrial Fibrillation). J Am Coll Cardiol. 2014;63(11):1082-1087.

7. Nagarakanti R, Ezekowitz MD, Oldgren J, Yang S, Chernick M, Aikens TH, Flaker G, et al. Dabigatran versus warfarin in patients with atrial fibrillation: an analysis of patients undergoing cardioversion. Circulation. 2011;123(2):131-136.

8. Cappato R, Ezekowitz MD, Klein AL, Camm AJ, Ma CS, Le Heuzey JY, Talajic M, et al. Rivaroxaban vs. vitamin $\mathrm{K}$ antagonists for cardioversion in atrial fibrillation. Eur Heart J. 2014;35(47):3346-3355.

9. Providencia R, Albenque JP, Combes S, Bouzeman A, Casteigt B, Combes N, Narayanan K, et al. Safety and efficacy of dabigatran versus warfarin in patients undergoing catheter ablation of atrial fibrillation: a systematic review and meta-analysis. Heart. 2014;100(4):324-335.

10. Naccarelli GV, Cappato R, Hohnloser SH, Marchlinski FE, Wilber DJ, Xiang J, Ma C, et al. Rationale and design of VENTURE-AF: a randomized, open-label, active-controlled multicenter study to evaluate the safety of rivaroxaban and vitamin $\mathrm{K}$ antagonists in subjects undergoing catheter ablation for atrial fibrillation. J Interv Card Electrophysiol. 2014;41(2):107-116.

11. Douketis JD, Spyropoulos AC, Spencer FA, Mayr M, Jaffer AK, Eckman MH, Dunn AS, et al. Perioperative management of antithrombotic therapy: Antithrombotic Therapy and Prevention of Thrombosis, 9th ed: American College of Chest Physicians Evidence-Based Clinical Practice Guidelines. Chest. 2012;141(2 Suppl):e326S$350 \mathrm{~S}$.

12. Birnie DH, Healey JS, Wells GA, Verma A, Tang AS, Krahn AD, Simpson CS, et al. Pacemaker or defibrillator surgery without interruption of anticoagulation. N Engl J Med. 2013;368(22):2084-2093.

13. Nascimento T, Birnie DH, Healey JS, Verma A, Joza J, Bernier ML, Essebag V. Managing novel oral anticoagulants in patients with atrial fibrillation undergoing device surgery: Canadian survey. Can J Cardiol. 2014;30(2):231236.

14. Rowley CP, Bernard ML, Brabham WW, Netzler PC, Sidney DS, Cuoco F, Sturdivant JL, et al. Safety of continuous anticoagulation with dabigatran during implantation of cardiac rhythm devices. Am J Cardiol. 2013;111(8):11651168.

15. Bauersachs R, Berkowitz SD, Brenner B, Buller HR, Decousus H, Gallus AS, Lensing AW, et al. Oral rivaroxaban for symptomatic venous thromboembolism. N Engl J Med. 2010;363(26):2499-2510.

16. Agnelli G, Buller HR, Cohen A, Curto M, Gallus AS, Johnson M, Masiukiewicz U, et al. Oral apixaban for the treatment of acute venous thromboembolism. N Engl J Med. 2013;369(9):799-808.

17. Buller HR, Prins MH, Lensin AW, Decousus H, Jacobson BF, Minar E, Chlumsky J, et al. Oral rivaroxaban for the treatment of symptomatic pulmonary embolism. N Engl J Med. 2012;366(14):1287-1297.

18. Schulman S, Kearon C, Kakkar AK, Mismetti P, Schellong S, Eriksson H, Baanstra D, et al. Dabigatran versus warfarin in the treatment of acute venous thromboembolism. N Engl J Med. 2009;361(24):2342-2352.

19. Chan AK, Monagle P. Updates in thrombosis in pediatrics: where are we after 20 years? Hematology Am Soc Hematol Educ Program. 2012;2012:439-443.

20. Agnelli G, Buller HR, Cohen A, Curto M, Gallus AS, Johnson M, Porcari A, et al. Apixaban for extended treatment of venous thromboembolism. N Engl J Med. 2013;368(8):699-708.

21. Raffini L, Huang YS, Witmer C, Feudtner C. Dramatic increase in venous thromboembolism in children's hospitals in the United States from 2001 to 2007. Pediatrics. 2009;124(4):1001-1008.

22. Sandoval JA, Sheehan MP, Stonerock CE, Shafique S, Rescorla FJ, Dalsing MC. Incidence, risk factors, and treatment patterns for deep venous thrombosis in hospi- 
talized children: an increasing population at risk. J Vasc Surg. 2008;47(4):837-843.

23. Decousus H, Frappe P, Accassat S, Bertoletti L, Buchmuller A, Seffert B, Merah A, et al. Epidemiology, diagnosis, treatment and management of superficial-vein thrombosis of the legs. Best Pract Res Clin Haematol. 2012;25(3):275-284.

24. Decousus H, Epinat M, Guillot K, Quenet S, Boissier C, Tardy B. Superficial vein thrombosis: risk factors, diagnosis, and treatment. Curr Opin Pulm Med. 2003;9(5):393397.

25. Kearon C, Akl EA, Comerota AJ, Prandoni P, Bounameaux H, Goldhaber SZ, Nelson ME, et al. Antithrombotic therapy for VTE disease: Antithrombotic Therapy and Prevention of Thrombosis, 9th ed: American College of Chest Physicians Evidence-Based Clinical Practice Guidelines. Chest. 2012;141(2 Suppl):e419S-494S.

26. Eriksson BI, Borris LC, Friedman RJ, Haas S, Huisman MV, Kakkar AK, Bandel TJ, et al. Rivaroxaban versus enoxaparin for thromboprophylaxis after hip arthroplasty. N Engl J Med. 2008;358(26):2765-2775.

27. Kakkar AK, Brenner B, Dahl OE, Eriksson BI, Mouret P, Muntz J, Soglian AG, et al. Extended duration rivaroxaban versus short-term enoxaparin for the prevention of venous thromboembolism after total hip arthroplasty: a double-blind, randomised controlled trial. Lancet. 2008;372(9632):31-39.

28. Lassen MR, Ageno W, Borris LC, Lieberman JR, Rosencher N, Bandel TJ, Misselwitz F, et al. Rivaroxaban versus enoxaparin for thromboprophylaxis after total knee arthroplasty. N Engl J Med. 2008;358(26):27762786.

29. Turpie AG, Lassen MR, Davidson BL, Bauer KA, Gent M, Kwong LM, Cushner FD, et al. Rivaroxaban versus enoxaparin for thromboprophylaxis after total knee arthroplasty (RECORD4): a randomised trial. Lancet. 2009;373(9676):1673-1680.

30. Lassen MR, Gallus A, Raskob GE, Pineo G, Chen D, Ramirez LM. Apixaban versus enoxaparin for thromboprophylaxis after hip replacement. $N$ Engl J Med. 2010;363(26):2487-2498.

31. Lassen MR, Raskob GE, Gallus A, Pineo G, Chen D, Hornick P. Apixaban versus enoxaparin for thromboprophylaxis after knee replacement (ADVANCE-2): a randomised double-blind trial. Lancet. 2010;375(9717):807-815.

32. Lassen MR, Raskob GE, Gallus A, Pineo G, Chen D, Portman RJ. Apixaban or enoxaparin for thromboprophylaxis after knee replacement. N Engl J Med. 2009;361(6):594604.

33. Eriksson BI, Dahl OE, Huo MH, Kurth AA, Hantel S, Hermansson K, Schnee JM, et al. Oral dabigatran versus enoxaparin for thromboprophylaxis after primary total hip arthroplasty (RE-NOVATE II*). A randomised, double-blind, non-inferiority trial. Thromb Haemost. 2011;105(4):721-729.

34. Eriksson BI, Dahl OE, Rosencher N, Kurth AA, van Dijk $\mathrm{CN}$, Frostick SP, Kalebo P, et al. Oral dabigatran etexilate vs. subcutaneous enoxaparin for the prevention of venous thromboembolism after total knee replacement: the RE-MODEL randomized trial. J Thromb Haemost. 2007;5(11):2178-2185.

35. Eriksson BI, Dahl OE, Rosencher N, Kurth AA, van Dijk $\mathrm{CN}$, Frostick SP, Prins MH, et al. Dabigatran etexilate versus enoxaparin for prevention of venous thromboembolism after total hip replacement: a randomised, doubleblind, non-inferiority trial. Lancet. 2007;370(9591):949956.

36. Ginsberg JS, Davidson BL, Comp PC, Francis CW, Friedman RJ, Huo MH, Lieberman JR, et al. Oral thrombin inhibitor dabigatran etexilate vs North American enoxaparin regimen for prevention of venous thromboembolism after knee arthroplasty surgery. J Arthroplasty. 2009;24(1):1-9.

37. Friedman RJ, Dahl OE, Rosencher N, Caprini JA, Kurth AA, Francis CW, Clemens A, et al. Dabigatran versus enoxaparin for prevention of venous thromboembolism after hip or knee arthroplasty: a pooled analysis of three trials. Thromb Res. 2010;126(3):175-182.

38. Turpie AG, Lassen MR, Eriksson BI, Gent M, Berkowitz SD, Misselwitz F, Bandel TJ, et al. Rivaroxaban for the prevention of venous thromboembolism after hip or knee arthroplasty. Pooled analysis of four studies. Thromb Haemost. 2011;105(3):444-453.

39. Anderson DR, Dunbar MJ, Bohm ER, Belzile E, Kahn SR, Zukor D, Fisher W, et al. Aspirin versus low-molecular-weight heparin for extended venous thromboembolism prophylaxis after total hip arthroplasty: a randomized trial. Ann Intern Med. 2013;158(11):800-806.

40. Stewart DW, Freshour JE. Aspirin for the prophylaxis of venous thromboembolic events in orthopedic surgery patients: a comparison of the AAOS and ACCP guidelines with review of the evidence. Ann Pharmacother. 2013;47(1):63-74.

41. Aspirin Product Monograph. Bayer Inc., Consumer Care. 2012.

42. American Academy of Orthopaedic Surgeons. Preventing venous thromboembolic disease in patients undergoing elective hip and knee arthroplasty. Evidence based guidelines and evidence report. (September 24, 2011). http:// www.aaos.org/research/guidelines/VTE/VTE_full_ guideline.pdf. Accessed November 1, 2013.

43. Falck-Ytter Y, Francis CW, Johanson NA, Curley C, Dahl OE, Schulman S, Ortel TL, et al. Prevention of VTE in orthopedic surgery patients: Antithrombotic Therapy and Prevention of Thrombosis, 9th ed: American College of Chest Physicians Evidence-Based Clinical Practice Guidelines. Chest. 2012;141(2 Suppl):e278S-325S.

44. Spencer FA, Lessard D, Emery C, Reed G, Goldberg RJ. Venous thromboembolism in the outpatient setting. Arch Intern Med. 2007;167(14):1471-1475.

45. Cohen AT, Spiro TE, Buller HR, Haskell L, Hu D, Hull $\mathrm{R}$, Mebazaa A, et al. Rivaroxaban for thromboprophylaxis in acutely ill medical patients. $\mathrm{N}$ Engl J Med. 2013;368(6):513-523.

46. Krantz MJ, Kaul S. The ATLAS ACS 2-TIMI 51 trial and the burden of missing data: (Anti-Xa Therapy to Lower Cardiovascular Events in Addition to Standard Therapy in Subjects With Acute Coronary Syndrome ACS 2-Throm- 
bolysis In Myocardial Infarction 51). J Am Coll Cardiol. 2013;62(9):777-781.

47. Skeppholm M, Kallner A, Malmqvist K, Blomback M, Wallen $\mathrm{H}$. Is fibrin formation and thrombin generation increased during and after an acute coronary syndrome? Thromb Res. 2011;128(5):483-489.

48. Oldgren J, Budaj A, Granger CB, Khder Y, Roberts J, Siegbahn A, Tijssen JG, et al. Dabigatran vs. placebo in patients with acute coronary syndromes on dual antiplatelet therapy: a randomized, double-blind, phase II trial. Eur Heart J. 2011;32(22):2781-2789.

49. Alexander JH, Lopes RD, James S, Kilaru R, He Y, Mohan P, Bhatt DL, et al. Apixaban with antiplatelet therapy after acute coronary syndrome. N Engl J Med. 2011;365(8):699-708.

50. Mega JL, Braunwald E, Wiviott SD, Bassand JP, Bhatt DL, Bode C, Burton $\mathrm{P}$, et al. Rivaroxaban in patients with a recent acute coronary syndrome. N Engl J Med. 2012;366(1):9-19.

51. Fitchett DH, Theroux P, Brophy JM, Cantor WJ, Cox JL, Gupta M, Kertland H, et al. Assessment and management of acute coronary syndromes (ACS): a Canadian perspective on current guideline-recommended treatment-part 1: non-ST-segment elevation ACS. Can J Cardiol. 2011;27(Suppl A):S387-401.

52. Fitchett DH, Theroux P, Brophy JM, Cantor WJ, Cox JL, Gupta M, Kertland H, et al. Assessment and management of acute coronary syndromes (ACS): a Canadian perspective on current guideline-recommended treatment--part 2: ST-segment elevation myocardial infarction. Can J Cardiol. 2011;27(Suppl A):S402-412.

53. Rao SV, Ohman EM. Anticoagulant therapy for percutaneous coronary intervention. Circ Cardiovasc Interv. 2010;3(1):80-88.

54. Yusuf S, Mehta SR, Chrolavicius S, Afzal R, Pogue J, Granger CB, Budaj A, et al. Effects of fondaparinux on mortality and reinfarction in patients with acute ST-segment elevation myocardial infarction: the OASIS- 6 randomized trial. JAMA. 2006;295(13):1519-1530.

55. Faxon DP, Eikelboom JW, Berger PB, Holmes DR, Jr., Bhatt DL, Moliterno DJ, Becker RC, et al. Antithrombotic therapy in patients with atrial fibrillation undergoing coronary stenting: a North American perspective: executive summary. Circ Cardiovasc Interv. 2011;4(5):522534.

56. Hansen ML, Sorensen R, Clausen MT, Fog-Petersen ML, Raunso J, Gadsboll N, Gislason GH, et al. Risk of bleeding with single, dual, or triple therapy with warfarin, aspirin, and clopidogrel in patients with atrial fibrillation. Arch Intern Med. 2010;170(16):1433-1441.

57. Orford JL, Fasseas P, Melby S, Burger K, Steinhubl SR, Holmes DR, Berger PB. Safety and efficacy of aspirin, clopidogrel, and warfarin after coronary stent placement in patients with an indication for anticoagulation. Am Heart J. 2004;147(3):463-467.

58. Dewilde WJ, Oirbans T, Verheugt FW, Kelder JC, De Smet BJ, Herrman JP, Adriaenssens T, et al. Use of clopidogrel with or without aspirin in patients taking oral anticoagulant therapy and undergoing percutaneous coronary intervention: an open-label, randomised, controlled trial. Lancet. 2013;381(9872):1107-1115.

59. World Health Organization. Global status report on noncommunicable diseases. 2010 (2011).

60. World Health Organization. Global atlas on cardiovascular disease prevention and control. (2011).

61. CCS (2005) Peripheral Arterial Disease Consensus Document. http://www.ccs.ca/download/consensus_conference/consensus_conference_archives/CCFinalPre_CJC_ Pub.pdf. Accessed November 62013.

62. Vandvik PO, Lincoff AM, Gore JM, Gutterman DD, Sonnenberg FA, Alonso-Coello P, Akl EA, et al. Primary and secondary prevention of cardiovascular disease: Antithrombotic Therapy and Prevention of Thrombosis, 9th ed: American College of Chest Physicians EvidenceBased Clinical Practice Guidelines. Chest. 2012;141(2 Suppl):e637S-668S.

63. Collaborative meta-analysis of randomised trials of antiplatelet therapy for prevention of death, myocardial infarction, and stroke in high risk patients. BMJ. 2002;324(7329):71-86.

64. Tanguay JF, Bell AD, Ackman ML, Bauer RD, Cartier R, Chan WS, Douketis J, et al. Focused 2012 update of the Canadian Cardiovascular Society guidelines for the use of antiplatelet therapy. Can J Cardiol. 2013;29(11):13341345.

65. Bhatt DL, Fox KA, Hacke W, Berger PB, Black HR, Boden WE, Cacoub P, et al. Clopidogrel and aspirin versus aspirin alone for the prevention of atherothrombotic events. N Engl J Med. 2006;354(16):1706-1717.

66. Anand S, Yusuf S, Xie C, Pogue J, Eikelboom J, Budaj A, Sussex B, et al. Oral anticoagulant and antiplatelet therapy and peripheral arterial disease. N Engl J Med. 2007;357(3):217-227.

67. A randomised, blinded, trial of clopidogrel versus aspirin in patients at risk of ischaemic events (CAPRIE). CAPRIE Steering Committee. Lancet. 1996;348(9038):1329-1339.

68. Arnold JM, Liu P, Demers C, Dorian P, Giannetti N, Haddad H, Heckman GA, et al. Canadian Cardiovascular Society consensus conference recommendations on heart failure 2006: diagnosis and management. Can J Cardiol. 2006;22(1):23-45.

69. Dai S, Walsh P, Wielgosz A, Gurevich Y, Bancej C, Morrison $\mathrm{H}$. Comorbidities and mortality associated with hospitalized heart failure in Canada. Can J Cardiol. 2012;28(1):74-79.

70. Lip GY, Gibbs CR. Does heart failure confer a hypercoagulable state? Virchow's triad revisited. J Am Coll Cardiol. 1999;33(5):1424-1426.

71. Gheorghiade M, Vaduganathan M, Fonarow GC, Greene SJ, Greenberg BH, Liu PP, Massie BM, et al. Anticoagulation in heart failure: current status and future direction. Heart Fail Rev. 2013;18(6):797-813.

72. Lip GY, Wrigley BJ, Pisters R. Anticoagulation versus placebo for heart failure in sinus rhythm. Cochrane Database Syst Rev. 2012;6:CD003336.

73. Homma S, Thompson JL, Pullicino PM, Levin B, Freudenberger RS, Teerlink JR, Ammon SE, et al. Warfarin and aspirin in patients with heart failure and sinus 
rhythm. N Engl J Med. 2012;366(20):1859-1869.

74. Cleland JG, Findlay I, Jafri S, Sutton G, Falk R, Bulpitt $\mathrm{C}$, Prentice C, et al. The Warfarin/Aspirin Study in Heart failure (WASH): a randomized trial comparing antithrombotic strategies for patients with heart failure. Am Heart J. 2004;148(1):157-164.

75. Cokkinos DV, Haralabopoulos GC, Kostis JB, Toutouzas PK. Efficacy of antithrombotic therapy in chronic heart failure: the HELAS study. Eur J Heart Fail. 2006;8(4):428432.

76. Massie BM, Collins JF, Ammon SE, Armstrong PW, Cleland JG, Ezekowitz M, Jafri SM, et al. Randomized trial of warfarin, aspirin, and clopidogrel in patients with chronic heart failure: the Warfarin and Antiplatelet Therapy in Chronic Heart Failure (WATCH) trial. Circulation. 2009;119(12):1616-1624.

77. Linkins LA, Dans AL, Moores LK, Bona R, Davidson BL, Schulman S, Crowther M. Treatment and prevention of heparin-induced thrombocytopenia: Antithrombotic Therapy and Prevention of Thrombosis, 9th ed: American College of Chest Physicians Evidence-Based Clinical Practice Guidelines. Chest. 2012;141(2 Suppl):e495S$530 \mathrm{~S}$.

78. Hart RG, Diener HC, Coutts SB, Easton JD, Granger CB, O'Donnell MJ, Sacco RL, et al. Embolic strokes of undetermined source: the case for a new clinical construct. Lancet Neurol. 2014;13(4):429-438.

79. Canadian Stroke Best Practices and Standards Working
Group. Canadian Best Practice Recommendations for Stroke Care. Chapter 3: Hyperacute Stroke Care. 2013.

80. The International Stroke Trial (IST): a randomised trial of aspirin, subcutaneous heparin, both, or neither among 19435 patients with acute ischaemic stroke. International Stroke Trial Collaborative Group. Lancet. 1997;349(9065):1569-1581.

81. CAST: randomised placebo-controlled trial of early aspirin use in 20,000 patients with acute ischaemic stroke. CAST (Chinese Acute Stroke Trial) Collaborative Group. Lancet. 1997;349(9066):1641-1649.

82. Lansberg MG, O'Donnell MJ, Khatri P, Lang ES, Nguyen-Huynh MN, Schwartz NE, Sonnenberg FA, et al. Antithrombotic and thrombolytic therapy for ischemic stroke: Antithrombotic Therapy and Prevention of Thrombosis, 9th ed: American College of Chest Physicians EvidenceBased Clinical Practice Guidelines. Chest. 2012;141(2 Suppl):e601S-636S.

83. Sandercock PA, Counsell C, Gubitz GJ, Tseng MC. Antiplatelet therapy for acute ischaemic stroke. Cochrane Database Syst Rev. 20083):CD000029.

84. Wang Y, Zhao X, Liu L, Wang D, Wang C, Li H, Meng $\mathrm{X}$, et al. Clopidogrel with aspirin in acute minor stroke or transient ischemic attack. N Engl J Med. 2013;369(1):1119.

85. Berge E, Sandercock P. Anticoagulants versus antiplatelet agents for acute ischaemic stroke. Cochrane Database Syst Rev. 2002;(4):CD003242. 